\title{
2017 was a very special year for powder diffraction
}

With this first Issue of Powder Diffraction Journal (PDJ) in 2018, it is worthwhile to reflect on last year. Along with publishing the four regular issues of Powder Diffraction two large Special Editions were also completed.

The regular PDJ issues continued the traditions of the journal and published many exciting developments and new crystallographic data along with informative International Reports and Calendars of upcoming meetings and workshops. There were several particularly noteworthy review articles last year. The first celebrated the $100^{\text {th }}$ anniversary of the invention of powder diffraction by Paul Scherre and Peter Debye along with that of Albert Hull. As Scherre and Debye's work is widely known the Review Article in PDJ summarized the 100-year landmark publication of Albert W. Hull contributions to establishing the field of Powder Diffraction. In the second 2017 issue, our community celebrated the $75^{\text {th }}$ Anniversary of the Powder Diffraction File ${ }^{\mathrm{TM}}$ and PDJ published the Review Article "Chemical analysis by diffraction: the Powder Diffraction File ${ }^{\mathrm{TM}}$ ". This laid out the evolution of the Powder Diffraction File, the coverage, and the powerful analytical features in the current version.

The first PDJ Special Edition published in 2017 was the Proceedings of the European Powder Diffraction Conference, EPDIC-15, which was held in Bari, Italy in June 2016. The second
PDJ Special Edition was the Proceedings of the Australian X-ray Analytical Association's meeting, AXAA-2017, held in Melbourne, Australia, February 2017. This proceedings edition is in publication and should be out before this first PDJ edition of 2018 appears. With the two conference proceedings, the number and the breadth of the science reported in Powder Diffraction expanded greatly. Congratulations to the Managing Editor Nicole Boris and the Cambridge University Press staff who worked especially long and hard to handle a large number of manuscripts published in 2017.

In late 2017, we received a proposal from Drs Craig Brown and Winnie Wong-Ng for PDJ to publish a special edition dedicated to Metal-Organic Framework crystallography (MOFs for short). MOFs have been a research topic for nearly two decades and select MOFs are now becoming commercial products. The role and value of crystallographic studies of MOFs will be highlighted. Please find the announcement of a call for papers for this future Special Edition of PDJ in this issue. We look forward to an exceptionally interesting collection of papers.

Camden Hubbard

Editor-in-Chief camden.hubbard@me.com 